\title{
Visitantes Florais de Erythrina speciosa Andr. (Leguminosae)
}

\author{
Maria J. Vitali-Veiga ${ }^{1}$ \\ Vera L.L. Machado ${ }^{1,2}$
}

\begin{abstract}
Flowering Visitors of Erythrina speciosa Andr., Leguminosae. In spite of Erythrina species exhibit morphologic attributes for adaptation to pollination by nectarivorous birds mentioned in the literature, E. speciosa is pollinated by lots of bees (Apinae and Meliponinae) which show a great urban occurrence. Systems of $E$. speciosa floral reproduction, fenology, diversity, frequency and constancy of insects visiting at different hours and flowering periods were studied. E. speciosa is autocompatible, but xenogamy is the predominant system of reproduction. A large diversity of insects visiting the inflorescences was observed, with predominance of bees. The bee species showed a higher frequency: Apis mellifera Linnaeus, 1758 (45,0\%), Trigona spinipes (Fabricius, 1793) (28,6\%), Trigona hyalinata (Lepeletier, 1836) (12,2\%) and the ant Zacryptocerus pusillus Klug, 1824 (2,8\%). Constant but not frequent were the bees (Apidae) Plebeia droryana (Friese, 1900), Friesella schrottkyi (Friese, 1900), Nannotrigona testaceicornis (Lepeletier, 1836), Tetragonisca angustula (Latreille, 1811), the wasps (Vespidae) Polybia paulista Ihering, 1896, Protopolybia exigua (de Saussure, 1854), Agelaia pallipes (Olivier, 1791), the ant (Formicidae) Pseudomyrmex sp. and the beetle (Chrysomelidae) Diabrotica speciosa (Germar, 1824). E. speciosa flowers were visited by hummingbirds (Trochilidae): Eupetomena macroura (Gmelin, 1788), Clorostilbon aureoventris (d'Orbigny \& Lafresnaye, 1838) and Amazilia sp. The birds Passer domesticus (Linnaeus, 1758) (Ploceidae) and Coereba flaveola (Linnaeus, 1758) (Emberizidae), also are present. The frequency and insect distribution were influenced by ambiental factors. Temperature, light, time, barometric pressure, relative humidity and wind velocity were significantly correlated with insect numbers. There is a visit sequence, by floral resource disponibility during the day, conditioned by transport ability, insect numbers and colony necessity, which begins by $A$. mellifera followed by meliponid bees. These bees make the pollination when they collect the pollen. There is a great animal variety which are sustained by flowers. It is suggested that $E$. speciosa is one important food source for urban fauna in winter, and so it should be utilized more frequently in streets, parks and gardens arborization. KEY WORDS. Pollination, Erythrina speciosa, bee, fenology, floral visitors
\end{abstract}

As espécies de Erythrina apresentam flores de cor vermelha ou laranja, néctar abundante e parecem estar adaptadas à polinização por pássaros nectarívoros. Erythrina speciosa Andr., encontrada no Brasil, ocorre naturalmente nos Estados da Bahia, Minas Gerais, Espírito Santo, Rio de Janeiro, São Paulo, Paraná e Santa Catarina (SCHULTZ 1963). Esta espécie é muito utilizada na arborização de ruas, jardins paulistas e cariocas (RIZZINI 1977) onde se observam muitos insetos visitantes.

1) Centro de Estudos de Insetos Sociais, Universidade Estadual Paulista. Avenida 24-A 1515, Caixa Postal 199, 13506-900 Rio Claro, São Paulo, Brasil. 
Assim, os estudos foram realizados em E. speciosa a fim de determinar a diversidade, freqüência e constância dos visitantes florais, o comportamento destes em relação à flor e a influência dos fatores ambientais nas visitas. Este estudo teve como enfoque conhecer a relação planta-polinizador em uma determinada área urbana para se verificar a partição de recursos entre os visitantes e identificação dos possíveis polinizadores.

\section{MATERIAL E MÉTODOS}

No jardim do Campus da Universidade Estadual Paulista em Rio Claro (São Paulo) foram realizadas observações e coletas dos visitantes florais de E. speciosa durante três anos consecutivos $(1989,1990,1991)$ durante o período forrageador (8 às 18 horas) em plantas denominadas E1, E2, E3, E4 e E5.

Nas coletas dos insetos foram utilizadas pinças e rede entomológica, posteriormente foram individualizados em frascos separados de hora em hora e fixados em Dietrich. Para cada hora anotou-se também a presença de aves bem como, os fatores ambientais: a luminosidade, temperatura, velocidade do vento, pressão barométrica e umidade relativa do ar. Posteriormente, os insetos foram transferidos para álcool $70 \%$ e identificados.

Para o acompanhamento das modificações florais, 10 botões florais foram marcados com fita crepe para a verificação do horário da antese (abertura da flor) até a senescência (queda das pétalas). Realizou-se a contagem do número de flores presentes em 10 inflorescências $(n=10)$ e do número de inflorescências em 21 plantas. A fenologia foi determinada através das fenofases: queda foliar, brotação, floração e frutificação.

Para a verificação da viabilidade dos grãos de pólen utilizou-se o método de RADFORDD et al. (1974). A presença ou não de células produtoras de odor (osmóforos) foi detectada utilizando-se o método de VogEL (1962, apud OLIVEIRA-FiLHO \& OliveIRA 1988) que cora as flores com vermelho neutro. A concentração de açúcares do néctar foi mensurada em equivalentes de sacarose (porcentagem de sólidos solúveis) com auxílio de um refratômetro. Para a verificação dos locais de absorção e reflexão de raios ultravioleta nas flores foi empregado uma solução de cloreto de ferro dissolvido em solução aquosa de éter sulfúrico a $1 \%$.

Flores, ainda em botão, foram envolvidas em sacos de papel impermeável para evitar o contato com os polinizadores. Durante a antese (marcada desde o botão floral prestes a se abrir até a abertura total da flor), 80 flores foram emasculadas para se testar a agamospermia. Outras flores $(\mathrm{n}=80)$ foram polinizadas manualmente com pólen da mesma flor e com pólen proveniente de flores diferentes ( $\mathrm{n}=$ 80) da mesma planta, para se testar a autopolinização e geitonogamia, respectivamente. Através da transferência de pólen de flores de plantas diferentes testou-se a polinização cruzada (xenogamia) $(n=80)$. Flores ensacadas sem emasculação $(n=$ 80) permaneceram como controle, a fim de se verificar a existência ou não de autopolinização espontânea. Essas flores tiveram seu desenvolvimento acompanhado até a formação de frutos. Posteriormente, o número de frutos maduros produzidos foi contado. Dez inflorescências foram marcadas e tiveram seu desenvolvimento acompanhado para a determinação da quantidade de flores e da taxa de produção de frutos em condições naturais. Flores com início de fruto em desenvolvimento (n 
$=100$ ), que tiveram corolas raspadas e danificadas por orifícios, foram acompanhadas até os frutos tornarem-se maduros.

O comportamento dos visitantes mais freqüentes, acima de $5 \%$ do total, foi observado (classificado segundo a terminologia de INOUYE 1980) várias vezes em diferentes horas do dia, procurando-se registrar a maneira pela qual o visitante se aproximava da planta, tempo gasto na visita a cada flor, a parte floral contactada, o número de flores visitadas antes de abandonar a inflorescência e o alimento procurado pelos visitantes.

Erythrina speciosa também foi observada durante a noite para a verificação da presença ou não de polinizadores noturnos, como por exemplo: presença de morcegos e mariposas.

Correlações entre os fatores ambientais (temperatura, luminosidade, pressão barométrica, umidade relativa do ar e velocidade do vento) com os insetos mais freqüentes foram realizadas. Para tal, utilizou-se o teste de correlação de Spearman (SIEGEL 1977). Para a estimativa da diversidade de espécies utilizou-se o Índice de Margalef (índice de riqueza $=\mathrm{R}$ ) e Índice de Shannon H' (índice de diversidade), segundo LUDWIG \& REYNOLDS (1988) comparados na fase de pico de florescimento.

\section{RESULTADOS E DISCUSSÃO}

O desenvolvimento das gemas florais que originam as inflorescências de $E$. speciosa ocorre no final de abril e começo de maio (Tab. I). Cada planta produziu em média 49,08 $\pm 26,07$ inflorescências $(n=21)$. Cada inflorescência produziu em média 207,5 $\pm 79,19$ flores $(\mathrm{n}=10)$, sendo que à medida que novos botões florais foram surgindo na sua porção superior, na parte mediana algumas flores encontravam-se abertas e outras já fecundadas. Cada inflorescência produziu 3,1 $\pm 6,29$ frutos $(\mathrm{n}=10)$, contendo cada um $9,4 \pm 1,77$ sementes, em média.

Tabela I. Fenologia de Erythrina speciosa Andr. (Leguminosae). (*) Registro a cada 10 dias do mês.

\begin{tabular}{|c|c|c|c|c|c|c|c|c|c|c|c|c|}
\hline Fenofases & Jan & Fev & Mar & $\mathrm{Abr}$ & Mai & Jun & Jul & Ago & Set & Out & Nov & Dez \\
\hline Desenvolvimento das gemas florais & & & & * & $* * *$ & & & & & & & \\
\hline Floraçăo & & & & & $*$ & $* *$ & $\cdots$ & $*$ & & & & \\
\hline Frutos pequenos e verdes & & & & & & & $*$ & $\cdots$ & $\cdot$ & & & \\
\hline Frutos desenvolvidos & & & & & & & & $*$ & $*$ & & & \\
\hline Frutos totalmente abertos & & & & & & & & & $* * *$ & $*$ & & \\
\hline Queda das sementes & & & & & & & & & $* *$ & $*$ & & \\
\hline Desenvolvimento de folhas novas & & & & & & & & & $*$ & $* * *$ & & \\
\hline Desenvolvimento de ramos novos & $* *$ & $* * *$ & * & & & & & & * & $* * \star$ & $* * * *$ & $* * \star$ \\
\hline Queda das folhas & & & $*$ & $* *$ & & & & & & & & \\
\hline
\end{tabular}

As flores são de tamanho médio, hermafroditas, com cinco pétalas de tamanhos desiguais. A pétala maior da flor apresenta-se muito túrgida e recobre toda a flor. Ela tem, a princípio, uma coloração vermelho vivo, atinge em média 5,9 centímetros. Internamente encontram-se as demais pétalas. $O$ cálice $($ de $1,2 \mathrm{~cm})$ apresenta muitos pêlos e nele o néctar é acumulado.

A antese das flores é diurna e se inicia no período das 9:00 às 10:30 horas (período em que o estigma já se encontra receptivo) e o tempo médio observado para a antese foi de $20,04 \pm 4,47$ horas $(n=10)$. A concentração de açúcares presentes 
no néctar é de $30 \%$ e o exame dos grãos de pólen após a antese indicou que $92,94 \%$ deles estavam viáveis. Esta alta viabilidade possivelmente aumenta a probabilidade da fertilização dos óvulos, assegurando a produção de sementes férteis, no caso de haver poucos grãos de pólen no estigma da flor.

$\mathrm{Na}$ pós-antese, as flores adquirem uma coloração mais escura (vermelho queimado), tornam-se enrugadas, flácidas e caem. As anteras tornam-se escurecidas (amarelo-queimado), murchas, e o estigma por sua vez, fica sem brilho e de colorido bege-escuro. O tempo médio observado para a pós-antese foi de $48,59 \pm 18,44$ horas $(\mathrm{n}=10)$.

Grandes quantidades de glândulas de odor estão presentes nos bordos da flor, tanto na parte superior quanto na inferior, com maior concentração no ápice. Pétalas e anteras absorvem e refletem a luz ultravioleta.

Erythrina speciosa apresenta um padrão de florescimento longo, com poucas flores se abrindo diariamente nas inflorescências. Dessa maneira, a floração representa, uma fonte regular de alimento que é disponivel por período extenso e oferecido em pequenas quantidades. Acredita-se que estas características induzem o polinizador a visitar outras flores de diferentes inflorescências promovendo assim, a polinização cruzada.

A autopolinização manual das flores de E. speciosa ocorreu em 3,75\% (Tab. II). Em condições naturais a produção de frutos foi de 1,42\%. São várias as explicações para essa baixa produção de frutos, tais como, a falta de recursos disponíveis na planta, a necessidade de uma determinada quantidade de pólen para atingir o estigma e/ou a existência de plantas hermafroditas com funcionalidade masculina. Segundo NeILl (1988), o tempo chuvoso e a alta umidade podem provocar aborto nas flores. A pequena quantidade de flores ( 3 a 4 ) abertas de cada vez pode ter favorecido a geitonogamia, pois esta ocorreu em $12,32 \%$. Entretanto, a xenogamia foi o sistema predominante de reprodução (36,92\%). As flores emasculadas não desenvolveram frutos, indicando que não ocorre a apomixia e que a polinização é de fato necessária.

Tabela II. Resultados dos experimentos sobre o sistema de reprodução de Erythrina speciosa Andr. (Leguminosae).

\begin{tabular}{lccc}
\hline \multicolumn{1}{c}{ Procedimento } & Flores & Frutos & Sucesso (\%) \\
\hline Autopolinizaçăo manual (pólen da mesma flor) & 80 & 3 & 3,75 \\
Geitonogamia (pólen de flores diferentes da mesma planta) & 73 & 9 & 12,32 \\
Xenogamia (pólen de flores de plantas diferentes) & 65 & 24 & 36,92 \\
Agamospermia (emasculação) & 60 & 0 & 0,00 \\
Controle (condiçס̃es naturais) & 70 & 1 & 1,42 \\
\hline
\end{tabular}

Verificou-se que, dentre os visitantes florais, os Hymenoptera foram mais representativos, com predominância dos Apidae (Tab. III). Os insetos mais freqüentes (acima de 5\% do total) foram: Apis mellifera Linnaeus, 1758, Trigona spinipes (Fabricius, 1793), Trigona hyalinata (Lepeletier, 1836) e Zacryptocerus pusillus Klug, 1824. Uma hipótese para explicar a baixa visitação das demais abelhas pode estar relacionada ao fato de que outras flores de diferentes espécies vegetais estão oferecendo recursos mais atrativos; competição com outras abelhas e/ou mesmo a baixa densidade populacional na área onde foram coletadas.

Revta bras. Zool. 17 (2): 369 - 383, 2000 
Tabela III. Visitantes florais de Erythrina speciosa Andr. (Leguminosae) durante o seu período de floração dos anos de 1989, 1990 e 1991. (E1, E2, E3, E4 e E5) Primeira a quinta coleta em Erythrina speciosa Andr.

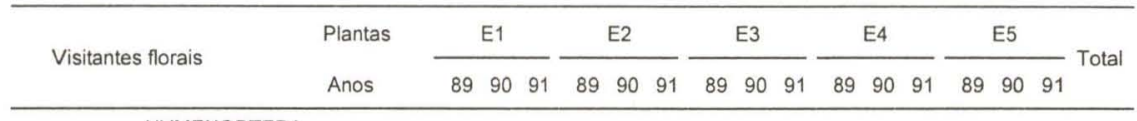

\section{Vespidae}

HYMENOPTERA

Polybia paulista Ihering, 1896

Polybia ignobilis (Haliday, 1836)

Polistes lanio (Fabricius, 1775

Polistes versicolor (Olivier, 1791)

Protopolybia exigua (de Saussure, 1854)

Protopolybia sedula (de Saussure, 1854)

Protonectarina sylveirae (de Saussure, 1854)

Agelaia pallipes (Olivier, 1791)

Mischocyttarus cerberus Richards, 1940

Mischocyttarus cassununga (Ihering, 1903)

Chalcididae

Braconidae

Cynipidae

Apidae

Apis mellifera Linnaeus, 1758

Trigona spinipes (Fabricius, 1793)

Trigona hyalinata (Lepeletier, 1836)

Nannotrigona testaceicornis (Lepeletier, 1836)

Tetragonisca angustula (Latreille, 1811)

Friesella schrottkyi (Friese, 1900)

Plebeia droryana (Friese, 1906)

Exomalopsis sp.

Halictidae

Augocloropsis sp.

Megachilidae

Formicidae

Formicinae

Zacryptocerus pusillus Klug, 1824

Camponotus sp.

Myrmicinae

Ponerinae

Pseudomyrmicinae

Pseudomyrmex sp.

Coreidae
Lygaeidae
Pentatomidae
Nabidae
Reduvidae

\section{LEPIDOPTERA}

Hesperiidae

Ctenuchidae

Danaidae

Lycaenidae

Tephritidae

Asilidae

Tachinidae

Muscidae

Syrphidae

COLEOPTERA

Chrysomelidae

Diabrotica speciosa (Germar, 1824)

Lagriidae

Lagria villosa Fabricius, 1783

$\begin{array}{rrrrrrrrrrrrrrrr}2 & - & - & 1 & 1 & - & 2 & 1 & 2 & - & - & - & - & - & 2 & 11 \\ - & - & - & - & 2 & - & - & - & - & - & 2 & - & - & - & 3 & 7 \\ - & - & - & - & - & - & - & 3 & - & - & - & - & - & - & - & 3 \\ - & 1 & 1 & - & - & - & - & - & - & - & - & 1 & - & - & - & 3 \\ - & - & 1 & 1 & 1 & - & 1 & 1 & 1 & 6 & - & - & - & - & 2 & 14 \\ - & 1 & - & - & - & - & - & - & - & - & 1 & - & - & - & - & 2 \\ - & - & - & - & - & 1 & - & - & - & - & - & - & - & - & - & 1 \\ 2 & 2 & 2 & 1 & - & 2 & 5 & 4 & - & 2 & 3 & - & - & - & 2 & 25 \\ - & - & - & - & - & 2 & - & - & - & 1 & - & - & - & - & - & 3 \\ - & - & - & - & - & - & - & 1 & - & - & - & - & - & - & - & 1 \\ - & - & - & - & - & - & - & - & - & - & - & - & 1 & - & - & 1 \\ - & - & - & - & - & - & - & - & - & - & - & - & 1 & - & 1 & 2 \\ - & - & - & 1 & - & - & - & - & - & - & - & - & - & - & - & 1\end{array}$

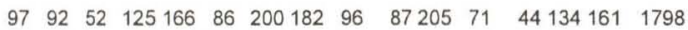

$\begin{array}{lllllllllllllll}188 & 2 & 86 & 244 & 2197 & 195 & 1 & 48 & 45 & 1 & 32 & 21 & - & 79 & 1141\end{array}$

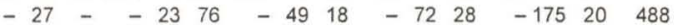

$\begin{array}{lllllllllllllll}1 & 4 & 2 & 5 & 1 & 4 & 1 & 3 & 2 & - & - & - & - & 3\end{array}$

- 1 - 51 - 1 - -1 - -1 10

- $-110-54-3-1-$ - 5 - 26

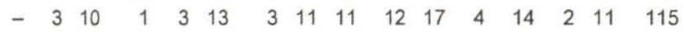

- - - - - - $1--$ - -1

- - - - - $1--2--$ - 3

$-1--\infty--$ - - - - - -1

- $-1-$ - - - - - - - 1

- - - - - - - - - - - 8 - 8

$\begin{array}{llllllllllllllll}1 & 30 & 3 & 1 & 44 & 3 & 3 & 14 & - & 5 & 5 & - & 312\end{array}$

- - - - - -1 - - - - - 1

- - $1-1$ - 1 - $15-$ - - - 9

$-\quad-\quad-\quad-\quad 1-$ - - - 1213

$-\quad 1--\quad-\quad-\quad-\quad-\quad-\quad-1$

$-1-26--1-11-42-18$

$1-$ - - - 1 - - - 1 - -14

- $-11-$ - 1 - - - - - 2

$-\quad-\quad-1-1-1-4-6$

- -1 - 1 - - - -1 - 2

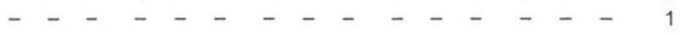

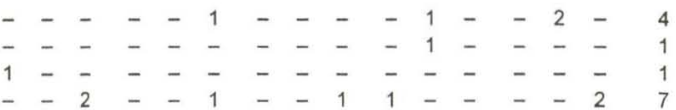

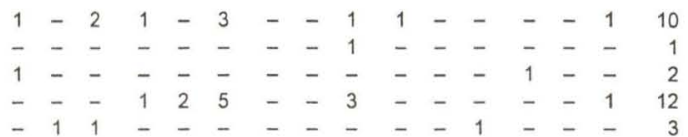

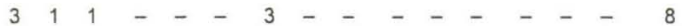

$-7-2-21-41-1-18$ 
Tabela III. Continuação.

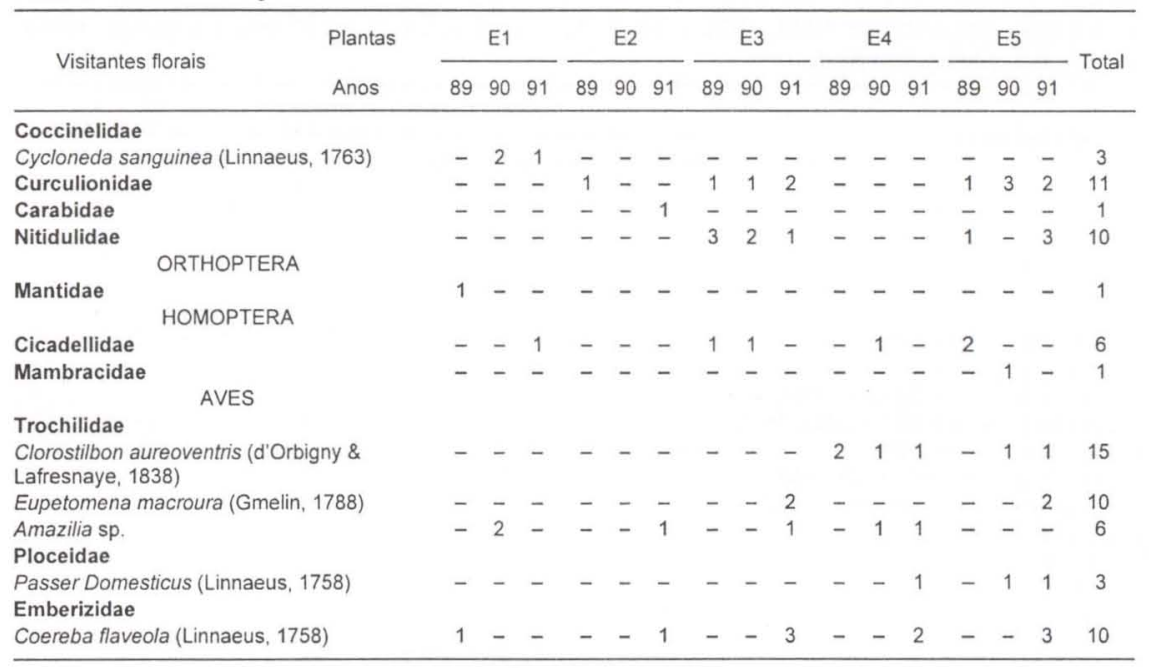

Plebeia droryana (Friese, 1900), Friesella schrottkyi (Friese, 1900), Nannotrigona testaceicornis (Lepeletier, 1836), Tetragonisca angustula (Latreille, 1811), Polybia paulista Ihering, 1896, Protopolybia exigua (de Saussure, 1854), Agelaia pallipes (Olivier, 1791), Pseudomyrmex sp. e o besouro Diabrotica speciosa (Germar, 1824) apesar de não serem freqüentes, foram constantes em todas as coletas.

A explicação para a variedade de insetos coletados nas flores provavelmente se deva à floração ocorrer no inverno, onde outras fontes e recursos disponíveis são escassos.

Os maiores índices de Margalef $(4,92)$ e de Shannon $(1,63)$ foram obtidos no ano de 1991, demonstrando que $E$. speciosa recebeu visita de uma fauna bastante diversificada, com elevado número de espécies diferentes e menor número de indivíduos das espécies dominantes.

\section{Apis mellifera}

Essa abelha foi muito abundante em $E$. speciosa e apresentou uma freqüência de $45 \%$. Visitou várias flores, permanecendo por um período de dois a três minutos. O difícil acesso ao alimento (pólen e néctar) devido ao pequeno diâmetro da flor, não permite a entrada de abelhas de tamanhos médio a grande. Então, A. mellifera se utiliza do seguinte recurso: pousa de cabeça para baixo na abertura da flor, utilizando suas pernas anteriores e suas mandíbulas para retirar o pólen das anteras que estão muito juntas e próximas do estigma. Ela pode permanecer durante todo o tempo de cabeça para baixo, inclusive para a transferência do pólen de uma perna para outra. Entretanto, algumas vezes o pólen é transferido para as corbículas durante o vôo e, posteriormente, ela pode voltar para a mesma flor ou realizar visitas a outras flores. Essa abelha, algumas vezes, força a abertura das pétalas das flores pois, quando estão fechadas não permitem a introdução das peças bucais e pernas 
para a coleta do pólen. A disposição das anteras permite a deposição do pólen na cabeça e região ventral de $A$. mellifera e o contato com o estigma é realizado através dessas regiões. Portanto, essa abelha foi considerada polinizadora de E. speciosa.

No período da tarde, $A$. mellifera foi observada coletando néctar através dos orifícios realizados por outros insetos (besouros e outras abelhas). Em 1989, A. mellifera apresentou correlação significativa com T. spinipes ( $\mathrm{rs}=0,799)$. Em 1990, A. mellifera correlacionou-se com $P$. droryana $(\mathrm{rs}=0,368)$ e $T$. hyalinata $(\mathrm{rs}=$ $0,559)$ e em 1991, somente com $T$. hyalinata $(\mathrm{rs}=0,455)$.

Os fatores ambientais que mostraram correlação significativa com a atividade de A. mellifera foram: horas (1989, rs $=0,601 ; 1990, \mathrm{rs}=-0,339$ e 1991, $\mathrm{rs}=-0,311$, luminosidade (1990, rs =0,587), pressão barométrica $(1989$, rs $=0,449$ e 1991 , rs $=$ $0,253$ ) e velocidade do vento (1989, rs $=0,479$ e 1991, $\mathrm{rs}=0,264)$ (Tabs IV a VI).

Tabela IV. Coeficiente de correlação de Spearman (rs) mostrando interrelacionamento de diferentes fatores ambientais influenciando a atividade de polinização de Trigona spinipes e Apis mellifera durante o periodo de junho a julho de 1989.

\begin{tabular}{|c|c|c|c|c|c|c|c|c|}
\hline & $\begin{array}{l}\text { Trigona } \\
\text { spinipes }\end{array}$ & $\begin{array}{c}\text { Apis } \\
\text { mellifera }\end{array}$ & Temperatura & Pressã̃o & Umidade & $\begin{array}{l}\text { Velocidade } \\
\text { vento }\end{array}$ & Luminosidade & Horas \\
\hline Trigona spinipes & 1,000 & & & & & & & \\
\hline Apis mellifera & $0,799^{*}$ & 1,000 & & & & & & \\
\hline Temperatura & $0,523^{*}$ & $0,226 \mathrm{~ns}$ & 1.000 & & & & & \\
\hline Pressăo & $0,211 \mathrm{~ns}$ & $0,449^{*}$ & $-0,470^{*}$ & 1,000 & & & & \\
\hline Umidade & $0,220 \mathrm{~ns}$ & $-0,150 \mathrm{~ns}$ & $0,763^{*}$ & $-0,703 *$ & 1,000 & & & \\
\hline Velocidade vento & $0,500^{\circ}$ & $0,479^{*}$ & $0,149 \mathrm{~ns}$ & $-0,023 \mathrm{~ns}$ & $0.068 \mathrm{~ns}$ & 1,000 & & \\
\hline Luminosidade & $0,789^{*}$ & $0,901 \mathrm{~ns}$ & $0,396 *$ & $0,469^{*}$ & $-0,160 \mathrm{~ns}$ & $0,383^{*}$ & 1,000 & \\
\hline Horas & $0,645^{*}$ & $0,601^{*}$ & $0,497^{*}$ & $0,218 \mathrm{~ns}$ & $0,176 \mathrm{~ns}$ & $0.129 \mathrm{~ns}$ & $0,594^{*}$ & 1,000 \\
\hline
\end{tabular}

$\left(^{*}\right)$ Significativo a nivel de 5\%; (ns) não significativo.

Tabela V. Coeficiente de correlação de Spearman (rs) mostrando interrelacionamento de diferentes fatores ambientais influenciando a atividade de polinização de Plebeia droryana, Zacryptocerus pusillus, Apis mellifera e Trigona hyalinata durante o periodo de junho a julho de 1990.

\begin{tabular}{|c|c|c|c|c|c|c|c|c|c|}
\hline & $\begin{array}{c}\text { Plebeia } \\
\text { droryana }\end{array}$ & $\begin{array}{c}Z . \\
\text { pusillus }\end{array}$ & $\begin{array}{c}\text { Apis } \\
\text { mellifera }\end{array}$ & $\begin{array}{c}\text { Trigona } \\
\text { hyalinata }\end{array}$ & Temp. & Pressão & Umidade & $\begin{array}{l}\text { Velocidade } \\
\text { vento }\end{array}$ & Luminos. Horas \\
\hline Plebeia droryana & 1,000 & & & & & & & & \\
\hline Z. pusillus & $0,117 \mathrm{~ns}$ & 1,000 & & & & & & & \\
\hline Apis mellifera & $0,368^{*}$ & $-0,018 \mathrm{~ns}$ & 1,000 & & & & & & \\
\hline Trigona hyalinata & $0,319^{*}$ & $-0,207 n s$ & $0,559^{*}$ & 1,000 & & & & & \\
\hline Temperatura & $0,474^{*}$ & $0,350^{\circ}$ & $-0,054 \mathrm{~ns}$ & $0,222 \mathrm{~ns}$ & 1,000 & & & & \\
\hline Pressăo & 0,294 * & $-0,379^{*}$ & $0,099 \mathrm{~ns}$ & $0,171 \mathrm{~ns}$ & $-0,457^{*}$ & 1,000 & & & \\
\hline Umidade & 0,362 * & $-0,141 \mathrm{~ns}$ & $0,168 \mathrm{~ns}$ & $-0,247^{\star}$ & $-0,724^{*}$ & 0,334 * & 1,000 & & \\
\hline Velocidade vento & $-0,059 \mathrm{~ns}$ & $-0,084 n s$ & $0,103 \mathrm{~ns}$ & $0,227 \mathrm{~ns}$ & $-0,018 \mathrm{~ns}$ & $0,443^{*}$ & $-0,155 \mathrm{~ns}$ & 1,000 & \\
\hline Luminosidade & $0,481 *$ & $0,047 \mathrm{~ns}$ & $0,587^{\star}$ & $0,697^{*}$ & $0,289 *$ & $0,148 \mathrm{~ns}$ & $-0,182 \mathrm{~ns}$ & $0,305^{*}$ & 1,000 \\
\hline Horas & $0,122 \mathrm{~ns}$ & $0,238+$ & $-0,339^{*}$ & $0,002 \mathrm{~ns}$ & $0,556^{*}$ & $-0,195 \mathrm{~ns}$ & $-0,195^{*}$ & $0,230 \mathrm{~ns}$ & $-0,154 \mathrm{~ns} 1,000$ \\
\hline
\end{tabular}

(*) Significativo a nivel de 5\%; (ns) não significativo; (+) cautela.

A temperatura, luminosidade, umidade relativa do ar, velocidade do vento, pressão atmosférica e horas do dia exercem influência sobre o forrageio pois os visitantes florais mostraram certa preferência por algumas horas. Apis mellifera apareceu em todas as horas de coleta e geralmente apresentou pico de visita no período da manhã (Figs 1 a 3). Mesmo em temperaturas baixas, $A$. mellifera iniciou 
sua atividade forrageadora. Segundo FAEGRI \& PIJL (1979) os polinizadores dependem de parâmetros meteorológicos assim, abaixo de uma determinada temperatura, ou a presença de vento ou chuva fortes, eles tornam-se inativos.

Tabela VI. Coeficiente de correlação de Spearman (rs) mostrando interrelacionamento de diferentes fatores ambientais influenciando a atividade de polinizaçăo de Plebeia droryana, Apis mellifera, Trigona spinipes e Trigona hyalinata durante o periodo de junho-julho de 1991.

\begin{tabular}{|c|c|c|c|c|c|c|c|c|c|c|}
\hline & $\begin{array}{l}\text { Plebeia } \\
\text { droryana }\end{array}$ & $\begin{array}{c}\text { Apis } \\
\text { mellifera }\end{array}$ & $\begin{array}{l}\text { Trigona } \\
\text { spinipes }\end{array}$ & $\begin{array}{c}\text { Trigona } \\
\text { hyalinata }\end{array}$ & Temperatura & Pressão & Umidade & $\begin{array}{l}\text { Velocidade } \\
\text { vento }\end{array}$ & Luminos. & Horas \\
\hline Plebeia droryana & 1,000 & & & & & & & & & \\
\hline Apis mellifera & $0,052 \mathrm{~ns}$ & 1,000 & & & & & & & & \\
\hline Trigona spinipes & $0,337^{*}$ & $0,057 \mathrm{~ns}$ & 1,000 & & & & & & & \\
\hline Trigona hyalinata & 0,256 * & $0,455^{*}$ & $-0,309^{*}$ & 1,000 & & & & & & \\
\hline Temperatura & 0,646 * & $-0,024 \mathrm{~ns}$ & $0,300^{*}$ & $0,274^{*}$ & 1,000 & & & & & \\
\hline Pressão & $0,021 \mathrm{~ns}$ & $0,253^{*}$ & $-0,023$ ns & $-0,434^{*}$ & $-0,434^{*}$ & 1.000 & & & & \\
\hline Umidade & $-0,399^{*}$ & $-0.130 \mathrm{~ns}$ & $-0,048 \mathrm{~ns}$ & $-0,307^{*}$ & $-0,827^{*}$ & $0,482^{*}$ & 1,000 & & & \\
\hline Velocidade vento & $0,187 \mathrm{~ns}$ & $0,264^{*}$ & $0,237+$ & $0,117 \mathrm{~ns}$ & $0,321^{*}$ & $-0,152 \mathrm{~ns}$ & $-0,293^{*}$ & 1,000 & & \\
\hline Luminosidade & $0,540^{*}$ & $-0,045 \mathrm{~ns}$ & $0,532 *$ & $0,162 \mathrm{~ns}$ & $0,312^{*}$ & $0,171 \mathrm{~ns}$ & $-0,166 \mathrm{~ns}$ & $-0,095 \mathrm{~ns}$ & 1,000 & \\
\hline Horas & $0,098 \mathrm{~ns}$ & $-0,311^{*}$ & $-0,171 \mathrm{~ns}$ & $0,156 \mathrm{~ns}$ & $0,553^{*}$ & $-0,384^{*}$ & $-0,756^{*}$ & $0,049 \mathrm{~ns}$ & $-0,039 \mathrm{~ns}$ & 1,000 \\
\hline
\end{tabular}

(*) Significativo a nivel de 5\%; (ns) não significativo; (+) cautela.

Apis mellifera tem maior capacidade de transporte e maior tamanho que os meliponideos ( $T$. spinipes, $T$. hyalinata, $P$. droryana, $F$. schrottkyi, $N$. testaceicornis e $T$. angustula) e forrageia logo que a planta inicia o fornecimento de pólen e de néctar, no período da manhã forrageia mais pólen. Sendo assim, aumenta as chances de polinizar E. speciosa, pois a coleta de pólen é realizada com mais intensidade no período da manhã e coincide com a antese das flores e com a receptividade do estigma.

A luminosidade em que $A$. mellifera foi encontrada forrageando foi de 3.000 lux a 110.000 lux, apresentando pico de atividade numa luminosidade (ótima) de 43.830 lux. A pressão barométrica variou de $70,8 \mathrm{~mm} \mathrm{Hg}$ a 71,4 mm Hg, com 71,0 $\mathrm{mm} \mathrm{Hg}$ de pressão ótima. Portanto, este fator ambiental não apresentou grandes variações. Forrageou no vento de até $1,6 \mathrm{~m} / \mathrm{s}$, mas, mostrou certa preferência por ausência de vento. BRITTAIN (1933, apud IWAMA 1977) concluiu que o vento é um importante fator na atividade externa de A. mellifera, influenciando o vôo dessas abelhas, mesmo em baixas velocidades.

\section{Trigona spinipes}

Foram freqüentes em $28,6 \%$ e apresentaram atividade forrageadora intensa no período, a partir das 10:00 horas, com pico de visita nas horas mais quentes do dia.

Trigona spinipes apareceram sempre em grupos nas flores. Elas andam sobre as flores durante um certo tempo como que "patrulhando-as" e, na maioria das vezes elas são encontradas "raspando" as pétalas e o cálice. Posteriormente, através dos orifícios deixados na base das pétalas, elas coletam o pólen e sorvem o néctar ali existente. Foram consideradas visitantes ilegítimos em vista do grande estrago que provocam. $T$. spinipes apresentou correlação significativa com $P$. droryana (rs $=$ $0,337)$ em 1991. 

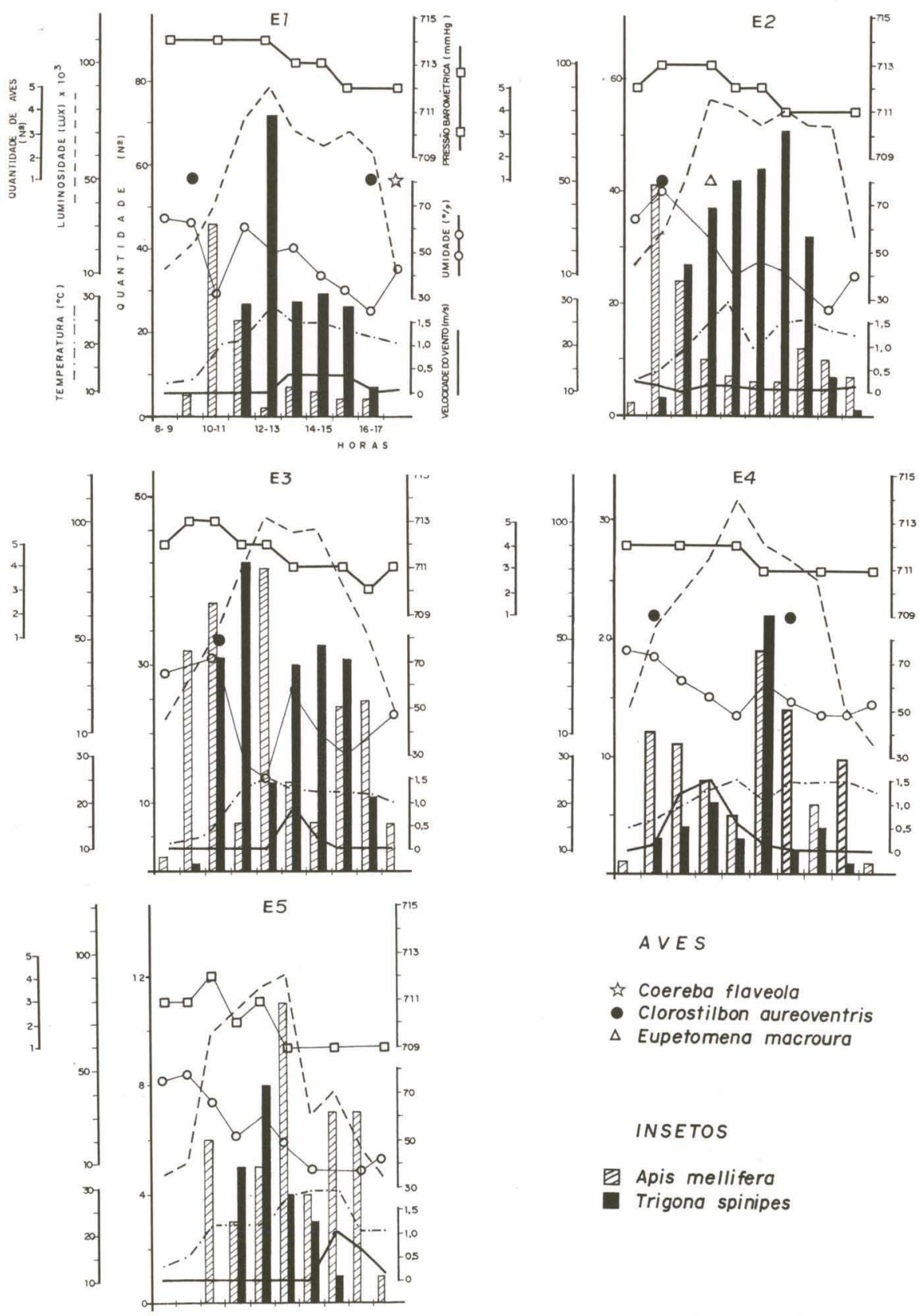

INSETOS

Apis mellifera

Trigona spinipes

Fig. 1. Distribuição das espécies mais freqüentes em diferentes horários, correlacionando com a luminosidade, temperatura, velocidade do vento, umidade e pressão barométrica, durante o periodo de floração de 1989 das plantas E1, E2, E3, E4, e E5 de Erythrina speciosa. 

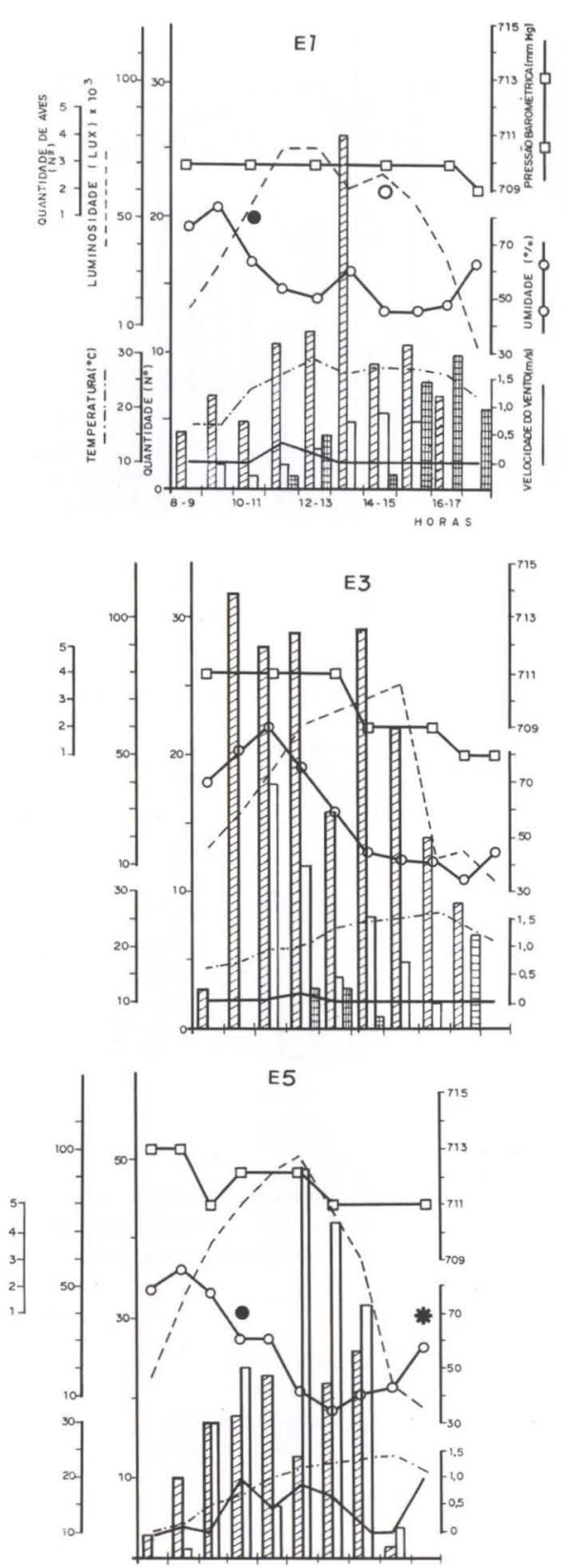
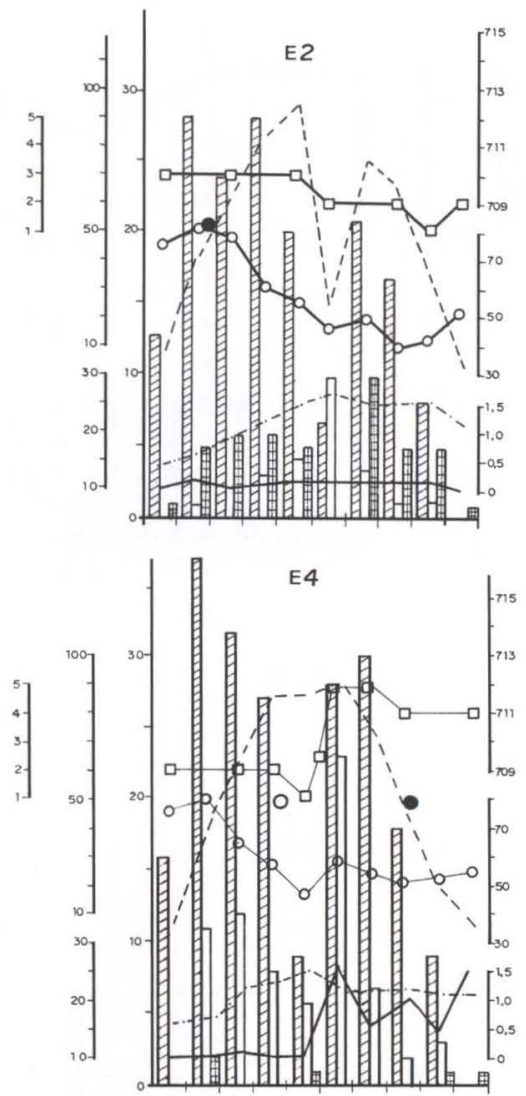

A VES

- Amazilia sp

- Clorostilbon aureoventris

INSETOS

$\square$ Apis mellifera

$\square$ Trigona hyalinata

团 Zacryptocerus pusillus

Fig. 2. Distribuição das espécies mais freqüentes em diferentes horários, correlacionando com a luminosidade, temperatura, velocidade do vento, umidade e pressão barométrica, durante o período de floração de 1990 das plantas E1, E2, E3, E4, e E5 de Erythrina speciosa. 

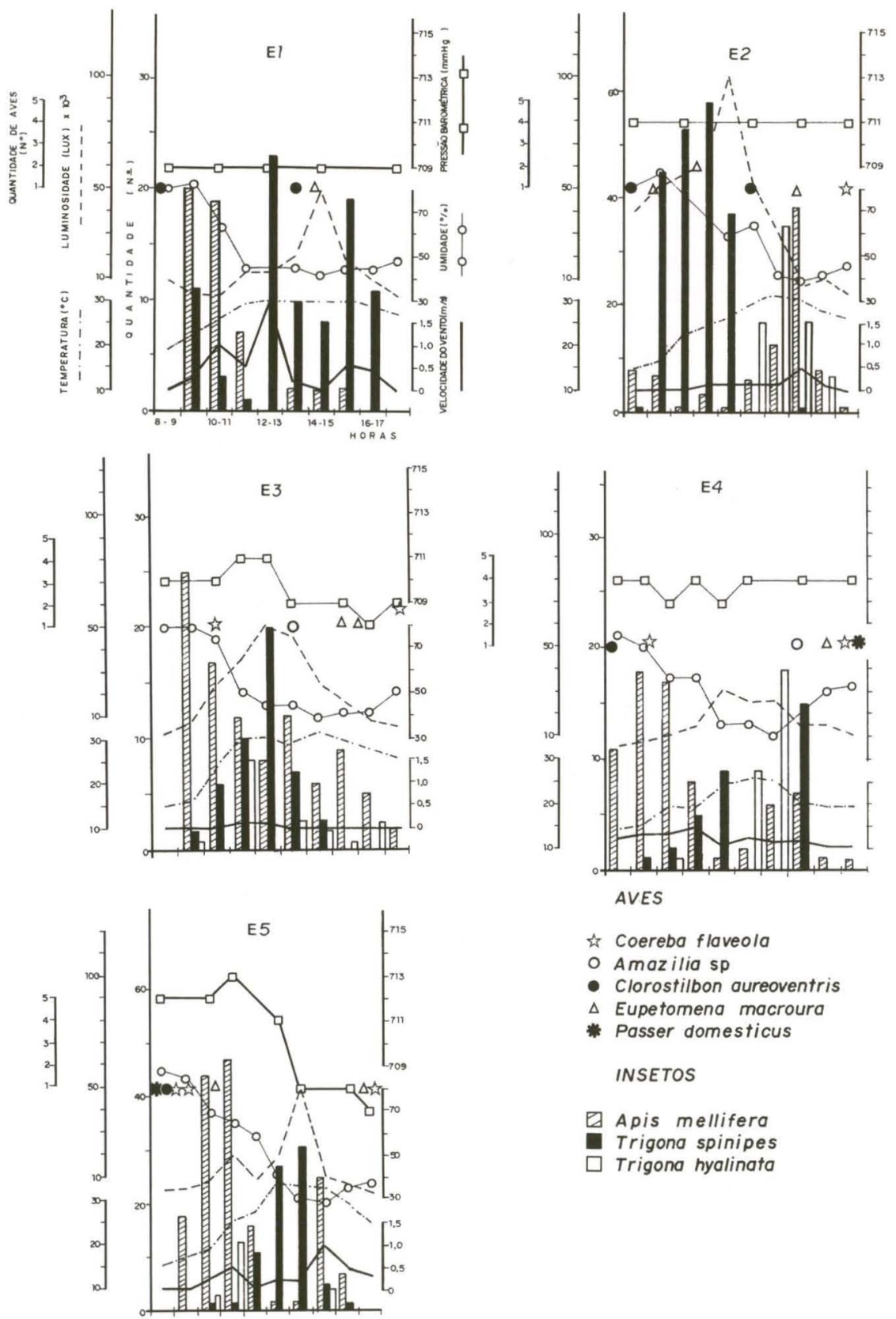

it Coereba flaveola

- Amazilia sp

- Clorostilbon aureoventris

$\triangle$ Eupetomena macroura

* Passer domesticus

INSETOS

$\square$ Apis mellifera

Trigona spinipes

Trigona hyalinata

Fig. 3. Distribuição das espécies mais freqüentes em diferentes horários, correlacionando com a luminosidade, temperatura, velocidade do vento, umidade e pressão barométrica, durante o período de floração de 1991 das plantas E1, E2, E3, E4, e E5 de Erythrina speciosa. 
Embora a produção natural de frutos de E. speciosa seja baixa, verificou-se que as flores $(n=100)$ com início de fruto em desenvolvimento que apresentaram corolas com orifícios, produziram frutos maduros normalmente $(28 \%)$.

Trigona spinipes apresentou correlação significativa com os seguintes fatores ambientais: temperatura $(1989, \mathrm{rs}=0,523$ e 1991, rs $=0,300)$, velocidade do vento $(1989, \mathrm{rs}=0,500$ e $1991, \mathrm{rs}=0,237)$, luminosidade $(1989, \mathrm{rs}=0,789 \mathrm{e}$ $1991, \mathrm{rs}=0,532)$ e com as horas $(1989, \mathrm{rs}=0,645)$. A temperatura variou de $14^{\circ} \mathrm{C}$ a $33^{\circ} \mathrm{C}$ mas a temperatura ótima encontrada para esta abelha foi de $24,8^{\circ} \mathrm{C}$. T . spinipes foi encontrada em dias em que a velocidade do vento foi de até $2 \mathrm{~m} / \mathrm{s}$, mas mostrou certa preferência por ausência de vento. A luminosidade em que essas abelhas exerceram atividade foi de 3.000 lux a 110.000 lux, respectivamente, apresentando 62.875 lux de luminosidade ótima.

\section{Trigona hyalinata}

Apresentaram uma frequiência de $12,2 \%$ e foram observadas forrageando com $T$. spinipes na mesma inflorescência, apresentando o mesmo tipo de comportamento de descobrir as anteras e o estigma que estavam protegidos pela pétala maior e, na base da flor, realizavam orifícios para a obtenção do néctar. Desta maneira, danificam as florações, entretanto, algumas abelhas utilizam-se das aberturas já existentes para obter o néctar. Também foram observadas comendo pólen diretamente das anteras.

Foi bastante representativa em 1990 e 1991 porém, não apresentou uma freqüência de distribuição constante através do dia. Iniciaram atividade forrageadora intensa nas horas mais quentes (a partir das 10:00 h), da mesma forma que $T$. spinipes.

Trigona hyalinata correlacionou-se com os seguintes fatores ambientais: umidade relativa do ar (1990, $r s=-0,247$ e 1991, $r s=-0,307)$, luminosidade (1990, $r s=0,697)$, temperatura e pressão barométrica $(1991, r s=0,274$ e $r s=-0,434$, respectivamente). A umidade relativa do ar variou consideravelmente, com a máxima de $83 \%$ e a mínima de $27 \%$, tendo $45,5 \%$ de umidade relativa ótima. A pressão barométrica não apresentou grandes variações, ficando entre $70,8 \mathrm{~mm} \mathrm{Hg}$ e 71,3 $\mathrm{mm} \mathrm{Hg}$, mas a pressão ótima encontrada para esta abelha foi de $71,0 \mathrm{~mm} \mathrm{Hg}$. A luminosidade que essas abelhas foram encontradas forrageando foi de 7.000 lux a 95.000 lux, sendo 53.500 lux a luminosidade ótima. Já, a temperatura variou desde $14^{\circ} \mathrm{C}$ até $32^{\circ} \mathrm{C}$, mas apresentou $25,5^{\circ} \mathrm{C}$ de temperatura ótima. Trigona hyalinata somente apresentou correlação significativa com P. droryana $(\mathrm{rs}=0,256) \mathrm{em} 1991$.

Acredita-se que a temperatura é um fator importante que exerce influência no comportamento das abelhas, funcionando como um estímulo para a sua saída das colméias e início do forrageamento.

\section{Zacryptocerus pusillus}

Foram freqüentes em 2,8\%. Entravam pela abertura existente na pétala, percorriam as anteras e posteriomente, dirigiam-se à base da flor a procura de néctar, podendo promover, eventualmente, a polinização. Em E. speciosa, foram observadas em média, três formigas $(n=20)$ em cada flor. 
Foram observadas também visitando toda a planta, por manter, provavelmente, seu ninho na cavidade natural do tronco. Segundo CorrEa (1969) as glândulas da base dos folíolos correspondem às estípulas eminentemente melíferas, tornando as espécies arbóreas de Erythrina mirmecófilas. As formigas são atraídas por esse néctar, patrulham a planta e protegem-nas dos herbívoros (RAVEN 1979).

Os fatores ambientais que mostraram correlação significativa com a atividade de Z. pusillus foram: temperatura (1990, rs $=0,350)$, pressão barométrica (1990, $\mathrm{rs}=0,379)$ e horas $(1990, \mathrm{rs}=0,238)$. A temperatura variou de $15^{\circ} \mathrm{C}$ a $33^{\circ} \mathrm{C}$ mas, a temperatura ótima em que essas formigas forragearam foi de $23,2^{\circ} \mathrm{C}$. A pressão barométrica foi um fator que não variou muito e essas formigas desenvolveram atividade desde $70,8 \mathrm{~mm} \mathrm{Hg}$ a 71,2 $\mathrm{mm} \mathrm{Hg}$, sendo 70,9 $\mathrm{mm} \mathrm{Hg}$ de pressão ótima.

Zacryptocerus pusillus teve representação significativa somente no ano de 1990 aparecendo em quase todos os horários com uma freqüência de distribuição mais ou menos constante a partir das 9:00 horas da manhã.

\section{Outros insetos visitantes}

As abelhas $P$. droryana, F. schrottkyi, $N$. testaceicornis e T. angustula; as vespas $P$. paulista, $P$. exigua e $A$. pallipes; a formiga $P$ seudomyrmex sp. e o besouro $D$. speciosa apesar de não serem freqüentes, foram constantes nas flores de $E$. speciosa.

Essas abelhas de pequeno tamanho conseguem entrar dentro da flor através da abertura existente na pétala e, da mesma forma que as formigas, elas andam pelas anteras e estigma, podendo levar, desta maneira, grãos de pólen aderidos em suas pernas e corpo.

Várias vespas sociais foram observadas freqüentemente nas flores a procura de néctar e/ou pêlos vegetais do cálice. Segundo NEILL (1988) as folhas das espécies de Erythrina possuem cera e pêlos. Durante a floração de E. speciosa algumas folhas caem tardiamente e o fato de serem portadoras de pêlos e cera talvez venha influenciar a visitação de alguns insetos que além de utilizarem o pólen e o néctar oferecidos pelas flores, podem usufruir também de outros benefícios oferecidos pelas folhas remanescentes.

Flores foram abertas manualmente de modo a expor os órgãos reprodutores e verificou-se a presença de seis a oito tripes por flor; inclusive nas flores que estavam fechadas. Devido ao pequeno tamanho, esses insetos podem entrar nas flores através de minúsculos orifícios e/ou fendas e andar sobre as anteras e estigma. Alguns foram encontrados cobertos de pólen. Portanto, devido suas dimensões corpóreas não se descarta a possibilidade de promoverem, eventualmente, a polinização. Costa Lima (apud CRESTANA \& BAitello 1988) comenta que os tripes podem intervir eficientemente na polinização, e também pode danificar as flores, promovendo a esterilidade e impedindo a formação de frutos.

Durante a noite, nenhum inseto visitante foi observado nas flores de $E$. speciosa, nem tampouco vertebrados noturnos como morcegos, nem acúmulo de néctar no cálice das flores. 


\section{Aves}

As flores de E. speciosa atraíram os beija-flores (Trochilidae) Eupetomena macroura (Gmelin, 1788) conhecido vulgarmente como "beija-flor-tesoura", Clorostilbon aureoventris (d'Orbigny \& Lafresnaye, 1838) "esmeralda-de-bico-vermeIho" e Amazilia sp.. Também apareceram visitando as flores Passer domesticus (Linnaeus, 1758) o conhecido "pardal doméstico" (Ploceidae) e a "cambacica", Coereba flaveola (Linnaeus, 1758) (Emberizidae).

A quantidade de néctar produzido por flor é aparentemente pequena para satisfazer às necessidades energéticas de um animal como o beija-flor. Portanto, para que os beija-flores realizem a polinização desta espécie há necessidade de que eles visitem um grande número de flores, o que não foi verificado em $E$. speciosa, pois eles visitam duas a três flores no máximo e depois pousam nos galhos e/ou fios de eletricidade e ficam "patrulhando e/ou descansando" por um período prolongado ou voam para outros lugares. Raras vezes foram observados inserindo o bico no ápice da flor deslizando-o até a base do nectário, de maneira a tocar os órgãos reprodutores com o bico e com a cabeça. HERNANDEZ \& Toledo (1979) estudando a polinização de E. leptorhiza De Candolle, 1825 verificaram que o beija-flor Amazilia beryllina (Deppe, 1830) foi um visitante ilegítimo da referida planta, pois insere o bico no cálice da flor, comportando-se como roubador de néctar.

Segundo WagNer (1946) quando o alimento é escasso, ou inadequado, beija-flores se nutrem de insetos e de outros animais pequenos. A grande freqüência de beija-flores nas florações do ano de 1991 talvez possa ser explicada pela presença de maior quantidade de Diptera os quais, além dos demais insetos, servem como complemento alimentar proteico.

Coereba flaveola perfurava danificando a base das flores ou somente se utilizava do orifício já existente para sorver o néctar. Segundo informação pessoal de E. Willis, C. flaveola esfrega ocasionalmente formigas ao corpo para aproveitarse da ação do ácido fórmico na troca das penas. Então, a freqüência desta ave pode ser devido ao fato de muitas formigas visitarem as flores de E. speciosa. O pardal $P$. domesticus foi observado coletando o néctar e/ou coletando insetos.

Portanto, verifica-se que os fatores ambientais exercem influência sobre o forrageio das abelhas. No caso de $A$. mellifera a explicação para a sua presença desde as primeiras horas da manhã pode ser pela coleta de maiores quantidades de pólen pois, a antese ocorre no período da manhã, apresentando também uma considerável quantidade de néctar.

Ocorre uma seqüência de visitas pela disponibilidade dos recursos florais durante o dia, condicionada pela capacidade de transporte, número de indivíduos e necessidades da colônia, primeiramente iniciada por $A$. mellifera, seguida pelos meliponídeos. Desta maneira, E. speciosa tem potencial para ser utilizada na arborização de ruas, parques e jardins, contribuindo, dessa forma, como uma fonte rica de pólen e néctar. Devido a grande variedade de animais sustentados pelas flores produzidas por esta população vegetal, pode-se sugerir que esta espécie de planta venha a se constituir no inverno, numa importante fonte alimentar para a fauna urbana. 
AGRADECIMENTOS. Ao Conselho Nacional de Desenvolvimento Científico e Tecnológico (CNPq) pelo auxílio financeiro. Ao Prof. Dr. José Manuel Macário Rebêlo pelo valioso auxílio na identificação de algumas abelhas. Ao Prof. Dr. Antonio Furlan e a Profa. Flávia Cristina Pinto Garcia pela identificação da espécie da planta estudada. Aos Profs. Dr. José Sílvio Govoni e Dr. Antonio Carlos Simões Pião pelo auxilio estatístico.

\section{REFERÊNCIAS BIBLIOGRÁFICAS}

Correa, M.P. 1969. Dicionário das Plantas Úteis do Brasil e das Exóticas Cultivadas. Rio de Janeiro, Irmãos Di Giorgio \& Cia Ltda Ed., 765p.

Crestana, C.S.M. \& J.B. Baitei.lo. 1988. Biologia floral de Nectandra mollis (H.b.k.) Nees ssp. Oppositifolia (NeEs) Hohwer (Lauraceae) na estação experimental de Moji-Guaçú, Estado de São Paulo. Bol. Técn. If. São Paulo 42: 121-137.

FAEgri, K. \& VAN DER PIJL. 1979. The principles of pollination ecology. Oxford, Pergamon Press, $224 \mathrm{p}$.

HERNANDEZ, H.M. \& V.M. TOLEDO. 1979. The role of nectar robbers and pollinators in the reproduction of Erythrina leptorhiza. Ann. Missouri Bot. Gard. 66: 512-520.

INOUYE, D.W. 1980. The terminology of floral lacerny. Ecology 61: 1251-1253.

IWAmA, S.A. 1977. A influência dos fatores climáticos na atividade externa de Tetragonisca angustula (Apidae, Meliponinae). Bol. Zool. Univ. São Paulo 2: 189-201.

LUDWIG, J.A. \& J.F. REYNOLDS. 1988. Statistical Ecology: a primer on methods and computing. New York, John Wiley \& Sons, 337p.

NEILL, D.A. 1988. Experimental studies on species relationships in Erythrina - Papilionoideae. Ann. Mo. Bot. Gard. 75: 886-969.

Oliveira-Filho, A.T. \& L.C.A. Oliveira. 1988. Biologia floral de uma população de Solanum lycocarpum St Hil (Solanaceae) em Lavras, MG. Rev. Bras. Bot. 11: 23-32.

Radford, A.E.; W.C. Dickinson; I.R. Massay Jr. \& C.R. Bf.l... 1974. Vascular Plants Systematics. New York, Harper \& Row, 891p.

Raven, P.H. 1979. Erythrina (Fabaceae: Faboideae): Introduction to symposium III. Ann. Missouri Bot. Garden 66: 417-421.

RIZZINI, C.T. 1977. Plantas Ornamentais. Rio de Janeiro, IBGE, 70p.

Schultz, A.R. 1963. Introdução ao Estudo da Botânica Sistemática. Porto Alegre, Ed. Globo S.A., $427 \mathrm{p}$.

SiegEt, S. 1977. Estatística não paramétrica (para as Ciências do Comportamento). Rio de Janeiro, Editora McGraw Hill Ltda, 350p.

WAGNER, H.O. 1946. Food and Feeding habits of Mexican Hummingbirds. Willson Bull. 58: 69-93.

Recebido em 01.VII.1999; aceito em 10.IV.2000. 